\title{
Three-dimensional hierarchical porous carbon derived from natural resources for highly efficient treatment of polluted water
}

\author{
Jiaxin $\mathrm{Li}^{1}$, Rudolf Holze ${ }^{2,3,4}$, Simbarashe Moyo ${ }^{1}$, Song Wang ${ }^{5^{*}}$, Sanxi $\mathrm{Li}^{5}$, Tao Tang ${ }^{6^{*}}$ and Xuecheng Chen ${ }^{1,5^{*}}$ (D)
}

\begin{abstract}
Background: Dealing with the ever-increasing water pollution has become an urgent global problem, especially the organic containing polluted water. Physical adsorption has become one of the most popular ways for removal of organic dyes from wastewater due to its low cost as well as high efficiency. However, the adsorption performance is still limited by the low specific surface area (SSA) and unsuitable pore size. Hence, it is still a challenge to synthesize active carbon (AC) with high SSA, suitable pore size distribution as well as low cost for polluted water treatment. Here, we report an efficient method to prepare AC with large SSA from jujube for removal of both cationic dye and anionic dye from aqueous solution. The present results demonstrate that biomass-derived hierarchical porous carbon has a real potential application for wastewater treatment.

Results: The as-prepared hierarchical porous structure carbon material (PC-500-6) shows a high specific surface area $\left(3203 \mathrm{~m}^{2} / \mathrm{g}\right)$ and pore size distribution in the range 0.8 to $3.0 \mathrm{~nm}$, while exhibiting an enhanced adsorption performance for both methylene blue $(\mathrm{MB})$ and methylene orange $(\mathrm{MO})$ from an aqueous solution. The maximum adsorption capacity even reaches $925.93 \mathrm{mg} / \mathrm{g}$ and $1281.39 \mathrm{mg} / \mathrm{g}$ for MB and MO, which was calculated from Langmuir model. Through analysis of the adsorption data, it was found that the corresponding adsorption kinetic fits the pseudo-second-order model very well.
\end{abstract}

Conclusions: It can be concluded that the adsorption of MB has a strong correlation with SSA, pore size distribution as well as the pore volume. The present study paved a practical way for wastewater treatment by using biomassderived hierarchical porous carbon.

Keywords: Biomass materials, Porous carbon, Methylene blue, Methylene orange, Waste water

\section{Background}

With the rapid development of industrialization, water pollution has become an ever-increasing global concern up to now $[1,2]$. More importantly, water pollution is

\footnotetext{
*Correspondence: wangsong@sut.edu.cn; ttang@ciac.ac.cn; xchen@zut.edu. pl

${ }^{1}$ Faculty of Chemical Technology and Engineering, West Pomeranian University of Technology, Piastów Ave. 42, 71-065 Szczecin, Poland

${ }^{5}$ School of Environment and Chemical Engineering, Shenyang University

of Technology, Shenyang 110870, China

${ }^{6}$ Changchun Institute of Applied Chemistry, Chinese Academy

of Sciences, Changchun 130022, China

Full list of author information is available at the end of the article
}

becoming more and more serious due to the existence of organic dyes stemming from paper-making, leather, rubber and cosmetics [3]. Most of them not only cause serious environmental problems, but also threaten human life $[4,5]$. Therefore, it is necessary to explore an environmentally friendly, low-cost and efficient method to remove organic dyes from contaminated water. In order to address this issue, various methods, such as chemical oxidation [6], photocatalysis [7-9], membrane filtration [10], and biological treatment have been proposed. However, the intrinsic limitations of these methods, such as high energy consumption, secondary pollution, and high cost have seriously hampered their 
practical applications. In contrast, physical adsorption has become one of the most popular ways for removal of organic dyes from wastewater due to its low cost as well as high efficiency [11-13]. Generally, activated carbon (AC) has been extensively used to treat polluted water owing to its high specific surface area (SSA) and high adsorption capacity [14-16]. Nevertheless, its adsorption performance is still poorer than expected due to the low SSA and unsuitable pore size. Hence, it is still highly desirable to produce AC with high SSA and suitable pore size distribution for polluted water treatment.

Biomass is considered as one of the potential raw materials to produce AC because of its abundance, wellorganized porous structure and renewable characteristics [13, 17-19]. Recently, various biomass materials such as coconut shells, [20] palm jujube seed, [21] peanut shell, [22] bean husk, [23] mangosteen peel [24] and waste coffee grounds [25] have been used as precursors to prepare AC. However, the adsorption performance of stateof-the-art AC is still lower than as-expected due to the relatively low surface area and unsuitable pore size distribution. Here, we report an efficient method to prepare AC with large SSA from jujube for removal of both cationic dye and anionic dye in aqueous solution, such as MB and MO. In order to obtain porous carbon with large SSA and suitable pore size distribution, two parameters are needed to be optimized: carbonization temperature and activation agent. In this contribution, jujube was used as carbon precursor for the production of porous carbon due to its highly porous 3D interconnected structure with specific attention to controlling these two parameters. Because of the hierarchical porous structure, jujubederived AC (PC-500-6) displays an excellent adsorption capacity as high as $925.93 \mathrm{mg} / \mathrm{g}$ and $1281.39 \mathrm{mg} / \mathrm{g}$ for MB and MO, which is one of the best reported results in the literature. Through analysis of the adsorption results, it was demonstrated that the adsorption of $\mathrm{MB}$ and $\mathrm{MO}$ fits the Langmuir model and pseudo-second order kinetic very well.

\section{Materials and methods}

\section{Preparation of carbonized materials (C-X)}

Fresh jujube was firstly washed with deionized water several times in order to remove dust and superficial impurities. Then the jujube was cut into thin sheets and frozen for $36 \mathrm{~h}$. In the next step, the freeze-drying process was used to prepare dry samples through sublimating the ice in the jujube sheets at $T<-50{ }^{\circ} \mathrm{C}$ overnight. The carbonized jujube sheets were obtained through carbonization at 500 and $800{ }^{\circ} \mathrm{C}$ in Ar for $2 \mathrm{~h}$ with a heating rate of 10 ${ }^{\circ} \mathrm{C} / \mathrm{min}$, samples are marked as $\mathrm{C}-\mathrm{X}\left(X=500\right.$ or $\left.800{ }^{\circ} \mathrm{C}\right)$.

\section{Preparation of porous carbon materials (PC-X-Y)}

For the preparation of $\mathrm{AC}$ samples, the mixture of $\mathrm{C}-\mathrm{X}$ and $\mathrm{KOH}$ powder with a mass ratio of $1: \mathrm{Y}$ was grinded $(Y=2,4$ and 6$)$. The chemical activation was carried out by heating the mixture under Ar. Typically, the above mixture was placed in a tube furnace and heated to $800^{\circ} \mathrm{C}$ with a heating rate of $10^{\circ} \mathrm{C} / \mathrm{min}$ and kept for $2 \mathrm{~h}$ at this temperature. After cooling down to room temperature, the carbon sample was taken out and treated with $1 \mathrm{M} \mathrm{HCl}$. In the next step, the AC samples were filtered and washed several times with deionized water. Finally, purified AC samples were obtained and denoted as porous carbon (PC-X-Y) after drying at $80{ }^{\circ} \mathrm{C}$ in vacuum, where $X$ and $Y$ represents the carbonization temperature and the mass ratio of $\mathrm{KOH} / \mathrm{C}-\mathrm{X}$, respectively.

\section{Characterization}

The morphology and surface element distribution of the porous carbon materials were characterized by field-emission scanning electron microscopy (SEM, XL30ESEM-FEG) with an acceleration voltage of $20 \mathrm{kV}$ and energy-dispersive X-ray (EDX, OXFORD INSTRUMENTS X-MAX) mapping. Initially, the samples were coated with a thin gold layer before SEM measurements. The HRTEM images were collected on a high-resolution transmission electron microscope (HR-TEM, FEI G2 S-Twin transmission electron microscope operated at $200 \mathrm{kV}$ ). XRD patterns of the samples were obtained using X-ray diffraction (XRD, PANalytical Benchtop $\mathrm{X}$-ray diffractometer) with $\mathrm{Cu} \mathrm{K \alpha}$ radiation at $60 \mathrm{kV}$ and $60 \mathrm{~mA}$. Raman spectra of the carbon materials were measured on a Raman analyzer (Renishaw micro-Raman spectrometer (excitation-beam wavelength: $532 \mathrm{~nm}$ ). The surface elemental composition was obtained by $\mathrm{X}$-ray photoelectron spectroscopy (XPS) carried out on a VG ESCALAB MK II spectrometer using $\mathrm{Al} K \alpha$ radiation at $10.0 \mathrm{kV}$ and $10 \mathrm{~mA}$. The textural properties were measured by nitrogen adsorption/desorption at $-196{ }^{\circ} \mathrm{C}$ on the Quantachrome Autosorb-1C-MS analyzer. The Brunauer-Emmett-Teller (BET) method and density function theory (DFT) were utilized to calculate the SSA and PSD of the samples, respectively. Before the adsorption measurement, all samples were degassed at $200{ }^{\circ} \mathrm{C}$ for $12 \mathrm{~h}$. The total pore volume was determined from nitrogen absorbed at a relative pressure of $p / p_{0}=0.99$. All calculated data were derived from the $\mathrm{N}_{2}$ isotherms when the test temperature was $0{ }^{\circ} \mathrm{C}$.

\section{Adsorption experiments}

The adsorption of MB or MO from aqueous solution on the AC samples was performed in a batch process. Typically, $20.0 \mathrm{mg} \mathrm{C}-\mathrm{X}$ or PC-X-Y was added into $50.0 \mathrm{ml} \mathrm{MB}$ 
or MO solution with desired initial concentrations under stirring in a flask. The $\mathrm{pH}$ was adjusted with $0.1 \mathrm{M} \mathrm{HCl}$ or $0.1 \mathrm{M} \mathrm{NaOH}$ until it reached 6. After the equilibrium was reached, $1.0 \mathrm{ml}$ of $\mathrm{MB}$ or $\mathrm{MO}$ solution was separated for subsequent analysis. The amount of MB or MO adsorption at equilibrium $q_{e}$ was calculated by the following equation:

$$
q_{e}=\frac{\left(C_{0}-C_{e}\right) V}{W}
$$

where $c_{0}$ and $c_{e}(\mathrm{mg} / \mathrm{l})$ are the liquid-phase concentration of MB before adsorption and at equilibrium, respectively. $V(\mathrm{~L})$ is the volume of the aqueous solution and $W(\mathrm{~g})$ is the mass of the adsorbent. The concentration of MB or MO was measured by UV-Vis-NIR spectrophotometry (Lambda 900, $\lambda_{\max }=665 \pm 1 \mathrm{~nm}$ or $\lambda_{\max }=461 \pm 1 \mathrm{~nm}$ ). The experiments were repeated twice for reproducibility purposes.

\section{Results and discussion Physical structure}

The surface structure and morphologies of the carbon samples were characterized by SEM and HRTEM, respectively. Figure 1a shows the SEM image of C-500, a cross-linked and microporous structure with open channel is clearly observed. After $\mathrm{KOH}$ activation, the porous carbons still remain with a 3D laminated structure as shown in Fig. 1b, c. The corresponding element mapping clearly shows the uniform distribution of carbon and oxygen element, which is shown in Additional file 1: Figure S1. HRETM was applied to give evidence of the morphology and structure of the carbon samples before and after activation in Fig. 1d-f. The carbon materials before and after activation are obviously different. The raw carbon material before activation is composed of mesopores and macropores, whereas the material after activation has more micropores. As shown in Fig. 1e, f, most of the regions consist of dark and light microstructures indicating that disordered graphitic structure and activation process produced more defects in AC samples. There are still graphitic layers with a spacing distance of $0.35 \mathrm{~nm}$ [26].

\section{Material characterization}

To determine the crystalline structure of the carbon materials, XRD patterns are recorded as displayed in Fig. 2a. There are two broad peaks at $2 \theta=26$ and $43^{\circ}$ in C-500, which correspond to the (002) and (100) diffraction planes of graphitic carbon, respectively [27]. After chemical activation, significant changes in XRD files were observed for PC-500-Y. As shown in Fig. 2a, both peaks almost disappear when the mass ratio of $\mathrm{KOH} / \mathrm{car}$ bon increases from 2 to 6 , indicating $\mathrm{KOH}$ has destroyed the graphitic structure and more defects have been produced. The above results agree very well with the TEM analyses (Fig. 1e, f).
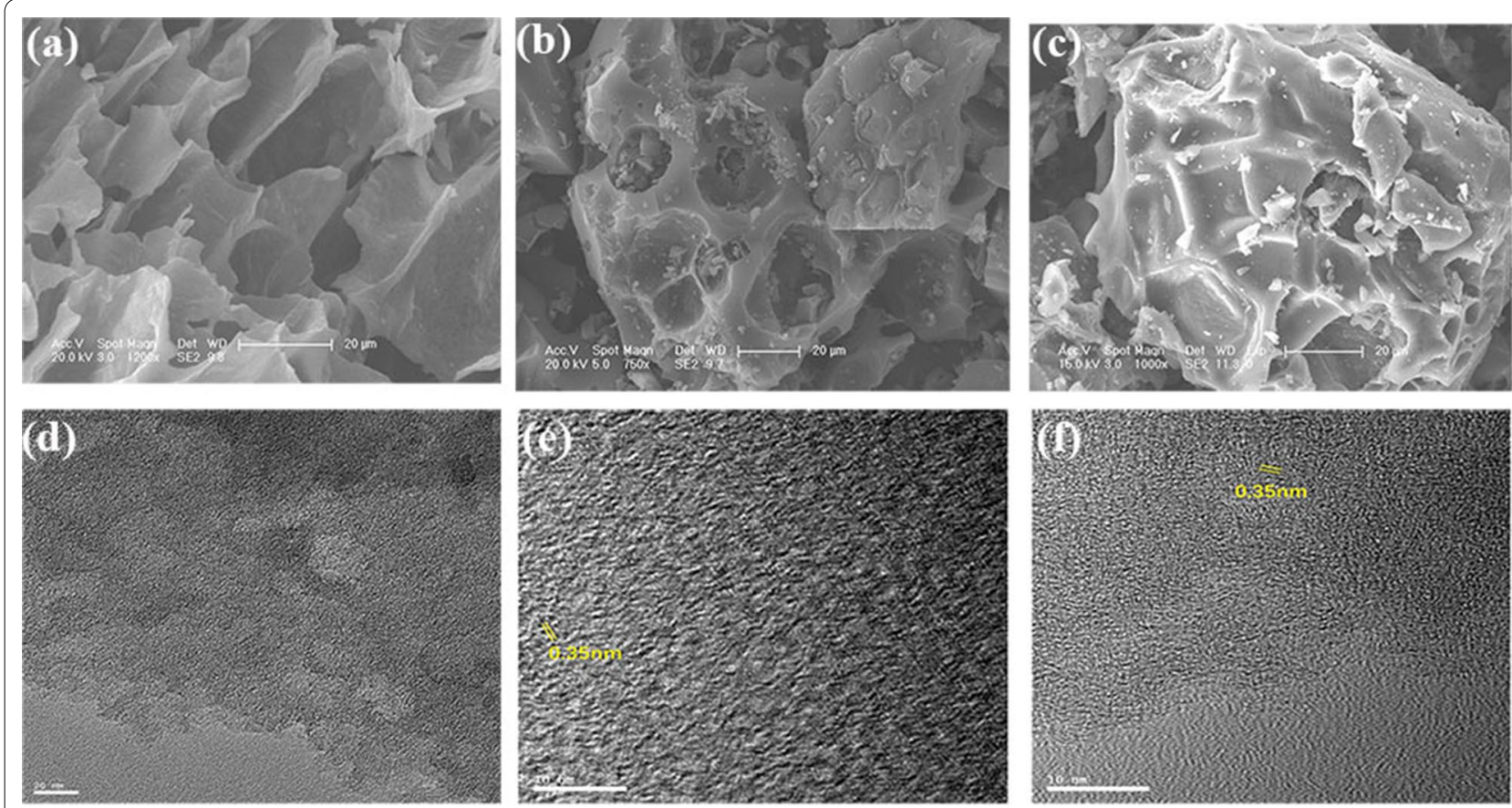

Fig. 1 SEM images of a C-500 and b PC-500-6 and c PC-800-6; HRTEM images of $\mathbf{d}$ C-500 and e PC-500-6 and $\mathbf{f}$ PC-800-6 

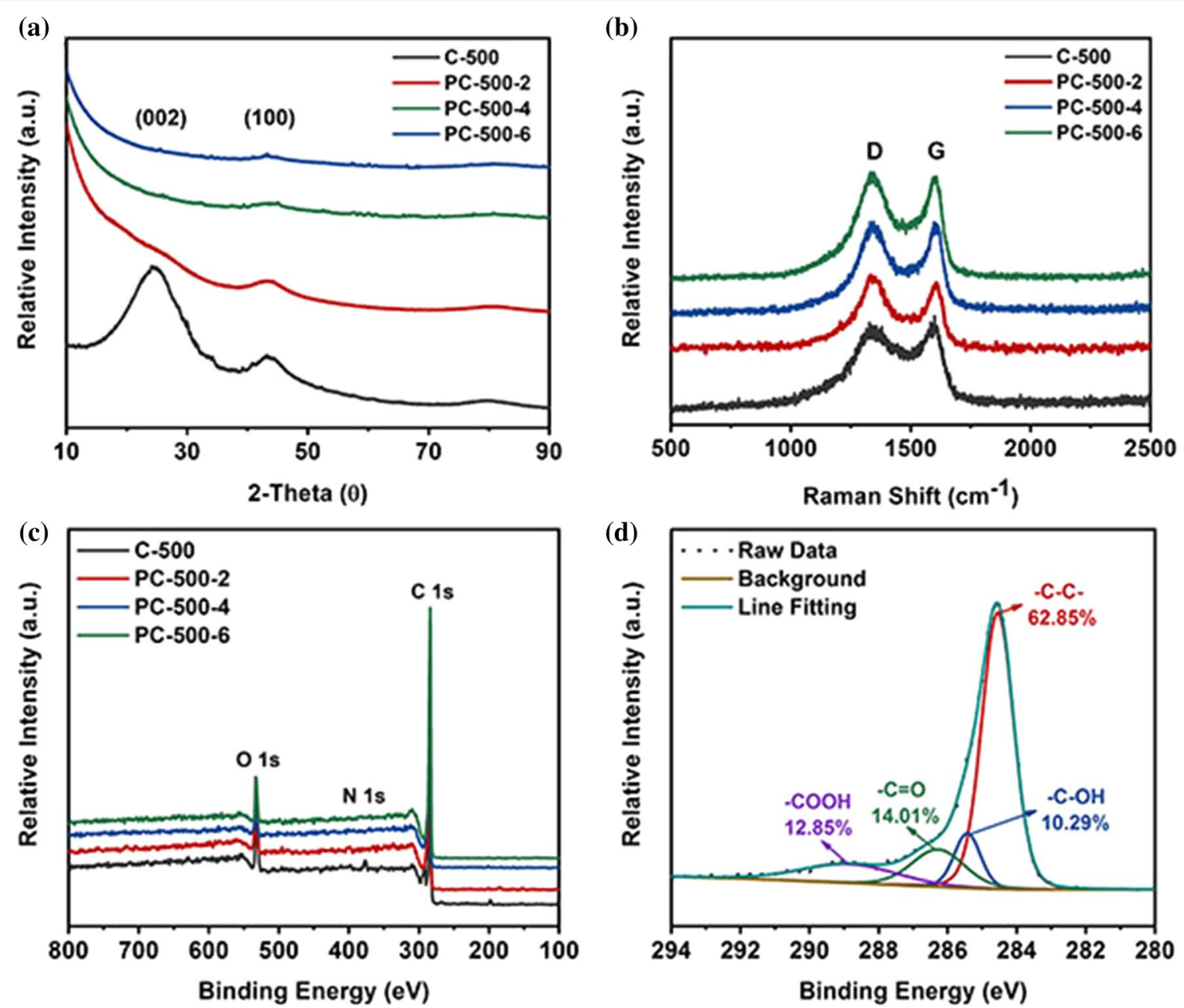

Fig. 2 a XRD curves, b Raman spectra, c full XPS spectra of C-500 and PC-500-Y. d High-resolution C 1s XPS spectra of PC-500-6

Raman spectroscopy can be employed to characterize the chemical structure of the carbon samples. As shown in Fig. $2 \mathrm{~b}$, there are two peaks located at $1350 \mathrm{~cm}^{-1}$ and $1580 \mathrm{~cm}^{-1}$ related to disordered carbon and $E_{2 g}$ mode of $\mathrm{sp}^{2}$-hybridized graphitic carbon, respectively $[28,29]$. The ratio of the $\mathrm{D}$ band to $\mathrm{G}$ band $\left(I_{D} / I_{G}\right)$ is commonly used to estimate the degree of disordering of the samples [30, 31]. The higher value of $I_{D} / I_{G}$ indicates the presence of more defects in carbon samples. The $I_{D} / I_{G}$ of C-500 is 1.05, which is much higher than that for PC-500-2 (0.84), PC-500-4 (0.82) and PC-500-6 (0.73), indicating that the chemical activation process led to more defects appearing in the samples.

The elemental composition of the carbon samples was estimated by XPS; the full survey spectrum and high-resolution XPS spectra of the samples are shown in Figs. 2c and $6 \mathrm{~b}$. There are three characteristic peaks at $285 \mathrm{eV}$, $400 \mathrm{eV}$ and $531 \mathrm{eV}$, which correspond to $\mathrm{C} 1 \mathrm{~s}, \mathrm{~N}$ 1s and $\mathrm{O}$ $1 \mathrm{~s}$, respectively. After $\mathrm{KOH}$ activation, nitrogen element almost disappears. As shown in Fig. 2d, the deconvolution of the $\mathrm{C} 1 \mathrm{~s}$ from $\mathrm{PC}-500-6$ indicated the presence of $-\mathrm{C}-\mathrm{C}-,-\mathrm{C}-\mathrm{OH},-\mathrm{C}=\mathrm{O}$ and $-\mathrm{COOH}$; the corresponding peaks are located at $284.6 \mathrm{eV}, 285.0 \mathrm{eV}, 286.8 \mathrm{eV}$ and $288.5 \mathrm{eV}$, respectively [32, 33]. In Fig. 6b, the $\mathrm{O} 1 \mathrm{~s}$ spectrum consists of two peaks located at $533.7 \mathrm{eV}$ and $532.3 \mathrm{eV}$, which correspond to $\mathrm{O}-\mathrm{C}=\mathrm{O}$ and $-\mathrm{C}-\mathrm{OH}$ groups. [34] From XPS analyses, it was found that AC samples are mainly composed of carbon as well as a few functional groups on the surface of the samples.

The $\mathrm{N}_{2}$ adsorption/desorption technique was used to investigate the porosity properties of the samples: the corresponding parameters of the $\mathrm{AC}$ samples are summarized in Table 1. As shown in Fig. 3a, b, AC samples show a typical type-I isotherm with high adsorption capacity in the low relative pressure range (0-0.05), corresponding to the existence of micropores [35]. Moreover, the broadening of the adsorption knee in the relatively lower pressure range (0.05-0.4) suggested the 
Table 1 Porosity properties of C-X and PC-X-Y samples

\begin{tabular}{lrlll}
\hline Sample & $\boldsymbol{S}_{\mathrm{BET}}{ }^{\mathbf{a}}\left(\mathbf{m}^{\mathbf{2}} / \mathbf{g}\right)$ & $\boldsymbol{V}_{\text {total }}{ }^{\mathbf{b}}\left(\mathbf{c m}^{\mathbf{3}} \mathbf{g}\right)$ & $\boldsymbol{V}_{(\mathbf{0 . 8 - 3 . 0 )}}{ }^{\mathrm{C}} / \boldsymbol{V}_{\text {total }}$ & $\begin{array}{l}\text { Average } \\
\text { pore size } \\
(\mathbf{n m})\end{array}$ \\
\hline C-500 & 94 & 0.02 & $87.7 \%$ & 4.3 \\
PC-500-2 & 2200 & 1.0 & $53.2 \%$ & 1.8 \\
PC-500-4 & 3090 & 1.7 & $88.1 \%$ & 2.00 \\
PC-500-6 & 3203 & 2.1 & $86.9 \%$ & 2.45 \\
C-800 & 57 & 0.2 & $64.2 \%$ & 10.1 \\
PC-800-2 & 1843 & 1.2 & $29.1 \%$ & 1.8 \\
PC-800-4 & 2291 & 1.6 & $44.8 \%$ & 1.9 \\
PC-800-6 & 2937 & 1.8 & $66.4 \%$ & 2.3 \\
\hline
\end{tabular}

a Specific surface area was calculated from BET method at $p / p_{0}=0.003-0.1$

${ }^{\mathrm{b}}$ Total pore volume at $p / p_{0}=0.99$

${ }^{c} V_{0.8-3.0}$ is the pore volume in the range of $0.8-3.0 \mathrm{~nm}$ formation of mesopores during the activation process. The pore size distributions also confirmed the existence of the mesopores in the AC samples [36, 37]. As the mass ratio of $\mathrm{KOH} / \mathrm{C}$ increases from 2 to 6 , the adsorption knee becomes wider, indicating more mesopores are generated in PC-500-6. This conclusion is consistent with details of the porosity parameters of $\mathrm{C}-\mathrm{X}$ and $\mathrm{PC}-\mathrm{X}-\mathrm{Y}$ in Fig. 3c, $\mathrm{d}$ and Table 1 . It can be clearly observed that the values of SSA and percentage of $V_{0.8-3.0}$ in $V_{\text {total }}$ go up when the $\mathrm{KOH} / \mathrm{C}$ mass ratio is enhanced. For example, $S_{B E T}$ of PC-500-2, PC-500-4 and PC-500-6 is 2200, 3090 and $3203 \mathrm{~m}^{2} / \mathrm{g}$, respectively. In the same time, the value of $V_{(0.8-3.0)} / V_{\text {total }}$ increase from 53.2 to $86.9 \%$.
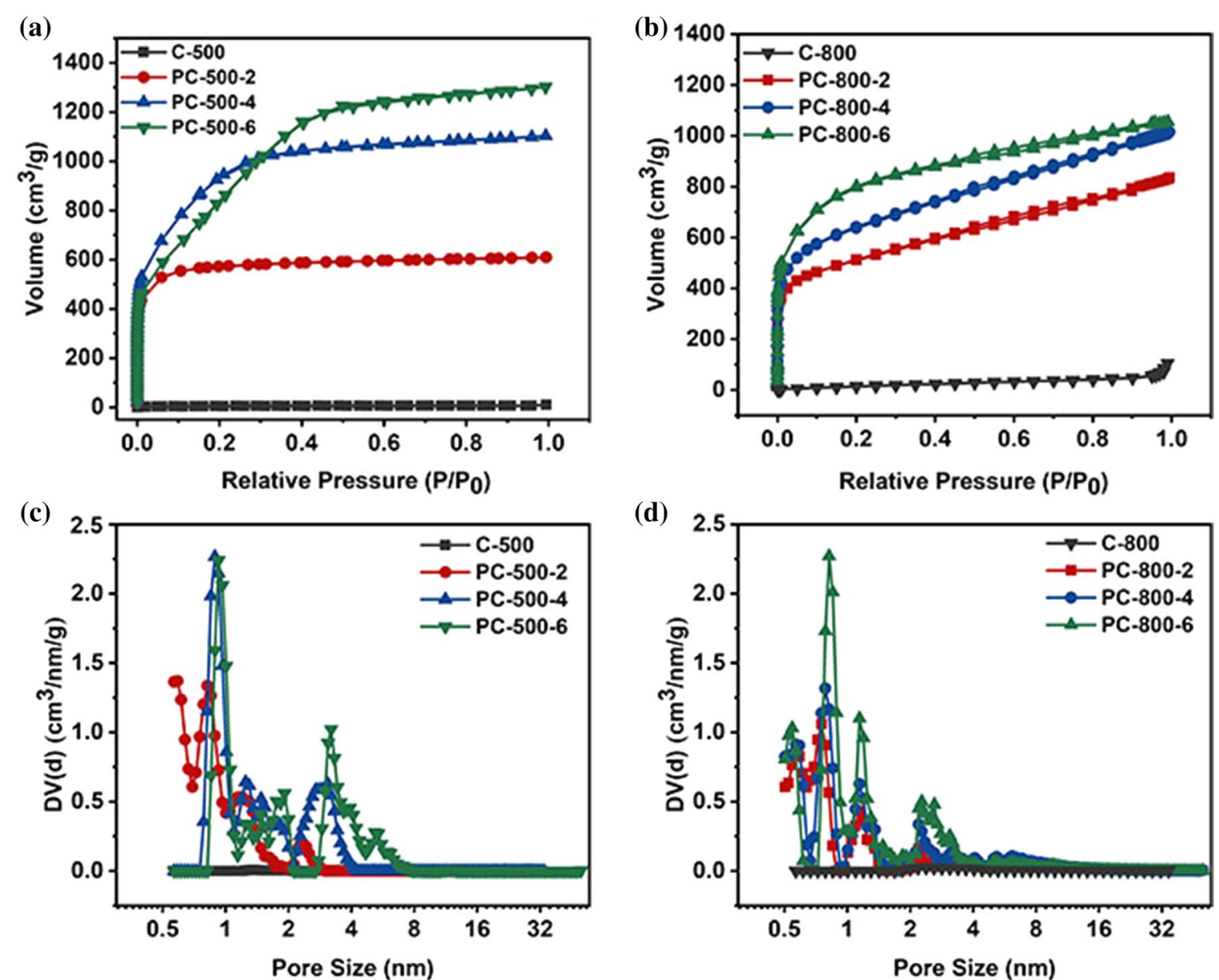

Fig. $3 \mathrm{~N}_{2}$ adsorption/desorption isotherms of a C-500 and PC-500-Y, b C-800 and PC-800-Y. Pore size distribution of c C-500 and PC-500-Y, d C-800 and $P C-800-Y$ 


\section{Adsorption isotherms}

The adsorption isotherm describes how the interaction happens between $\mathrm{AC}$ samples and $\mathrm{MB}$ molecules the interface of liquid and solid phase during the adsorption process. In this article, three adsorption isotherms were used to analyze the adsorption data by nonlinear equations, such as Langmuir, Freundlich and Temkin isotherms.

The Langmuir model based on the assumption of monolayer adsorbates on a homogenous surface $[10,38]$ was tested. It is expressed by:

$$
q_{e}=q_{m} \frac{K_{L} c_{e}}{1+K_{L} c_{e}},
$$

where $K_{L}$ is the Langmuir adsorption constant (L/ $\mathrm{mg}$ ), and $q_{m}$ is Langmuir monolayer adsorbate capacity $(\mathrm{mg} / \mathrm{g})$.

After linearization of the Langmuir isotherm Eq. (2), the linear equation is:

$$
\frac{C_{e}}{q_{e}}=\frac{1}{q_{m} K_{L}}+\frac{1}{q_{m}} c_{e} .
$$

Multilayer adsorbates are described using the Freundlich model, which assumes an energetically heterogeneous surface. The Freundlich isotherm is represented by the following equation $[39,40]$ :

$$
q_{e}=K_{F} c_{e}^{1 / n} .
$$

The linear form is as following:

$$
\ln q_{e}=\ln K_{F}+\frac{1}{n} \ln c_{e},
$$

where $q_{e}$ is the equilibrium concentration of dye on the adsorbent $(\mathrm{mg} / \mathrm{g}), c_{e}$ is the equilibrium concentration of dye in solution $(\mathrm{mg} / \mathrm{l}), K_{F}$ and $\mathrm{n}$ are the Freundlich constants, which represent the adsorption capacity $(\mathrm{mg} / \mathrm{g})$ and the adsorption strength, respectively. The magnitude of $1 / n$ quantifies the favorability of adsorption and the degree of heterogeneity of the adsorbent surface.

The well-known form of the Temkin isotherm indicates the effects of some indirect adsorbate/adsorbate interactions on adsorption isotherms, the isotherm can be expressed as:

$$
q_{e}=\frac{R T}{b_{T}} \ln \left(\mathrm{K}_{\mathrm{T}} \mathrm{c}_{\mathrm{e}}\right) .
$$

The linear form of the Temkin equation is: [41]

$$
q_{e}=B_{T} \ln K_{T}+B_{T} \ln c_{e},
$$

where $B_{T}=R_{T} / b_{T}, T$ is the absolute temperature in $K, R$ is the universal gas constant $(8.314 \mathrm{~J} / \mathrm{mol} / \mathrm{K}), K_{T}$ is the equilibrium binding constant $(\mathrm{L} / \mathrm{mg})$, and $B_{T}$ is related to the heat of adsorption and constant value of Temkin isotherm.

Figure 4, Table 2, Additional file 1: Figure S5, Table S1 display the equilibrium adsorption data for $\mathrm{C}-\mathrm{X}$ and $\mathrm{PC}$ $\mathrm{X}-\mathrm{Y}$ linearly fitted to Langmuir, Freundlich and Temkin isotherms and corresponding parameters, respectively. As shown in Fig. 4a, the amount of adsorbed MB increases at a low initial concentration and reaches a plateau at a high equilibrium concentration, indicating Langmuir isotherms fitted well with the experiment data [42]. It means that the adsorption took place at the specific homogenous sites within the carbon materials and $\mathrm{MB}$ molecules as a single monolayer [43]. According to Fig. 4b-d, the Langmuir isotherms exhibit higher correlation coefficients $\left(R^{2}>0.999\right)$ than Freundlich or Temkin model, indicating that Langmuir isotherm is a more precise model to describe the adsorption process. Moreover, maximum adsorption capacity is found to increase from 751.88 to $925.93 \mathrm{mg} / \mathrm{g}$ with the increase of mass ratio (KOH/carbon) from 2 to 6 (Table 2). Among all AC samples, PC-500-6 exhibits the highest adsorption capacity of MB $(925.93 \mathrm{mg} / \mathrm{g})$, more than 35 times higher than that of $\mathrm{C}-500$. The adsorption results indicate that PC-500-6 delivers superior performance in dye adsorption compared to published results (Additional file 1: Table S2). In addition, optical photographs were taken before and after $\mathrm{MB}$ adsorption (Additional file 1: Figure S2a). For example, after the adsorption of MB with an initial concentration of $300 \mathrm{mg} / \mathrm{L}$ on PC-500-6, the polluted water became clear and colorless, which further revealed the efficient adsorption and distinct discoloration for wastewater using PC-500-6.

In order to investigate the adsorption kinetics of $\mathrm{MB}$ adsorption on $\mathrm{AC}$, the experimental kinetic data are fitted to pseudo-first-order and pseudo-second-order kinetic models. The applied kinetic equations are as follows.

The pseudo-first-order kinetic model can be expressed as [44]:

$$
\ln \left(\mathrm{q}_{\mathrm{e}}-\mathrm{q}_{\mathrm{t}}\right)=\ln \left(\mathrm{q}_{\mathrm{e}}\right)-\mathrm{k}_{1} \mathrm{t},
$$

where $q_{t}$ is the amount of dye on the adsorbent at $t$ min $(\mathrm{mg} / \mathrm{g})$, and $k_{1}$ is the rate constant of the pseudo-firstorder kinetic model for the adsorption $\left(\min ^{1}\right)$. The values of $q_{e}$ and $k_{1}$ can be determined from the intercept and the slope of the linear plot of $\ln \left(q_{e}-q_{t}\right)$ versus $t$, respectively. The pseudo-second-order kinetic model is represented by the following equation $[45,46]$ :

$$
\frac{t}{q_{t}}=\frac{1}{k_{2} q_{e}^{2}}+\frac{t}{q_{e}}
$$


(a)

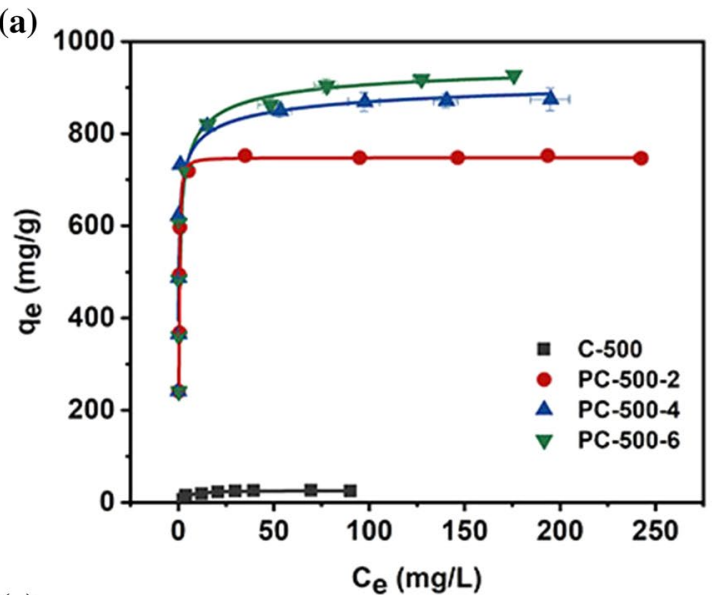

(c)

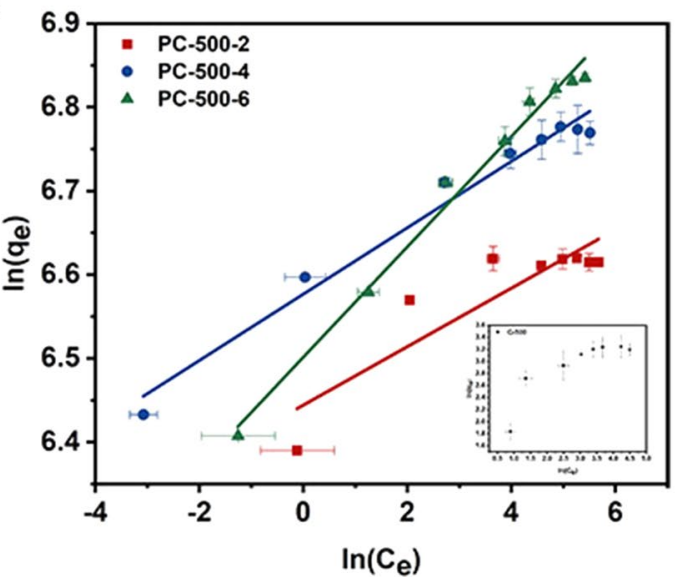

(b)

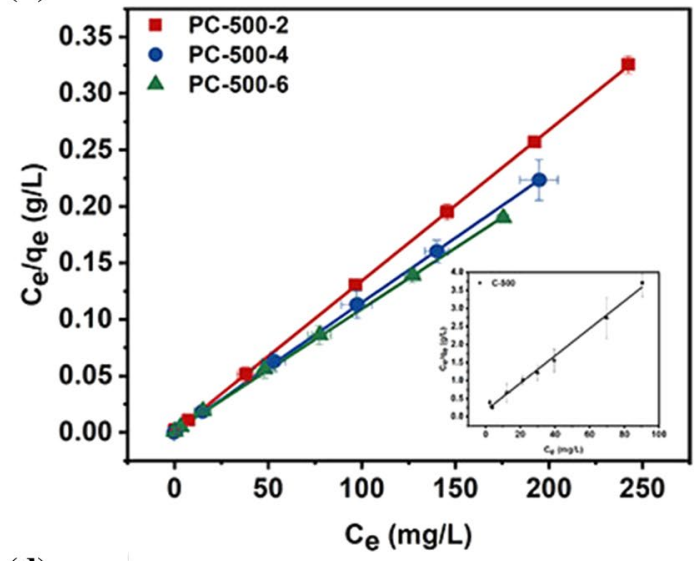

(d)

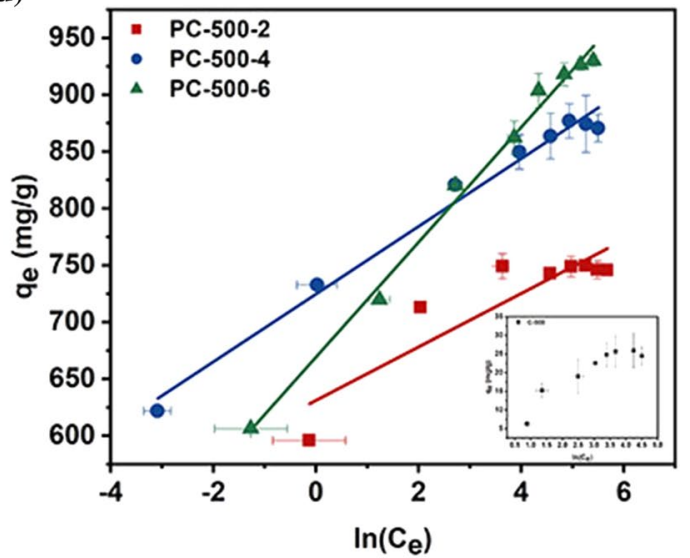

Fig. 4 a Equilibrium adsorption isotherms, b Langmuir, c Freundlich $\mathbf{d}$ and Temkin isotherms of MB on C-500 and PC-500-Y. (20 mg of C-500 or PC-500-Y added to a $50 \mathrm{ml} \mathrm{MB}$ solution (10-80 or 100-550 mg/L) at a designated concentration after stirring for $12 \mathrm{~h}$.)

Table 2 Langmuir, Freundlich and Temkin isotherm parameters for C-500 and PC-500-Y for MB adsorption

\begin{tabular}{llllll}
\hline Isotherm & Parameter & \multicolumn{4}{l}{ Adsorbent } \\
\cline { 3 - 6 } & & C-500 & PC-500-2 & PC-500-4 & PC-500-6 \\
\hline Langmuir & $q_{m}(\mathrm{mg} / \mathrm{g})$ & 26.39 & 751.88 & 877.19 & 925.93 \\
& $\mathrm{~K}_{\mathrm{L}}(\mathrm{L} / \mathrm{mg})$ & 0.215 & 2.057 & 2.144 & 0.864 \\
& $\mathrm{R}^{2}$ & 0.99308 & 0.99998 & 0.99991 & 0.99964 \\
\multirow{5}{*}{ Freundlich } & $1 / \mathrm{n}$ & - & 0.03491 & 0.03963 & 0.0659 \\
& $\mathrm{~K}_{\mathrm{F}}(\mathrm{mg} / \mathrm{g}(\mathrm{L} /$ & - & 628.4974 & 717.6759 & 665.6246 \\
& $\mathrm{mg}) 1 / \mathrm{n})$ & & & & \\
\multirow{5}{*}{ Temkin } & $\mathrm{R}^{2}$ & - & 0.76173 & 0.97225 & 0.98617 \\
& $\mathrm{~B}_{\mathrm{T}}$ & - & 23.52 & 29.79 & 50.56 \\
& $\mathrm{~K}_{\mathrm{T}}(\mathrm{L} / \mathrm{mg})$ & - & $1.07^{*} 10^{9}$ & $1.52^{* 1} 10^{8}$ & $2.83^{* 1} 10^{4}$ \\
& $\mathrm{R}^{2}$ & - & 0.77325 & 0.98262 & 0.99095 \\
\hline
\end{tabular}

where $k_{2}$ is the rate constant of the pseudo-second-order kinetic model for adsorption $(\mathrm{g} / \mathrm{mg} / \mathrm{min})$. The slope and intercept of the linear plot of $t / q_{t}$ against $t$ yield the values of $q_{e}$ and $k_{2}$, respectively.
Figure 5, Additional file 1: Figure S6 and Figure S7 display the kinetic curves and linear fits for the adsorption of $\mathrm{MB}$ by $\mathrm{PC}-\mathrm{X}-\mathrm{Y}$ at $20{ }^{\circ} \mathrm{C}$ using the pseudo-first-order and pseudo-second-order models. Table 3, Additional file 1: Tables S3, S4 present the coefficients for the pseudo-firstorder and pseudo-second-order kinetic models. All the experimental data comply better with the pseudo-second-order kinetic model in terms of higher correlation coefficient values $\left(R^{2}>0.99\right)$. This demonstrates that the pseudo-second-order kinetic model is more suitable to describe the adsorption behavior of MB by the PC-X-Y.

\section{Adsorption thermodynamics of the PC-500-6}

During the adsorption process, thermodynamic parameters are important in controlling the adsorption behavior. The adsorption free energy $(\Delta G)$, the adsorption entropy $(\Delta S)$, and the adsorption enthalpy $(\Delta H)$ were calculated using Eqs. (10) and (11) expressed as follows: 

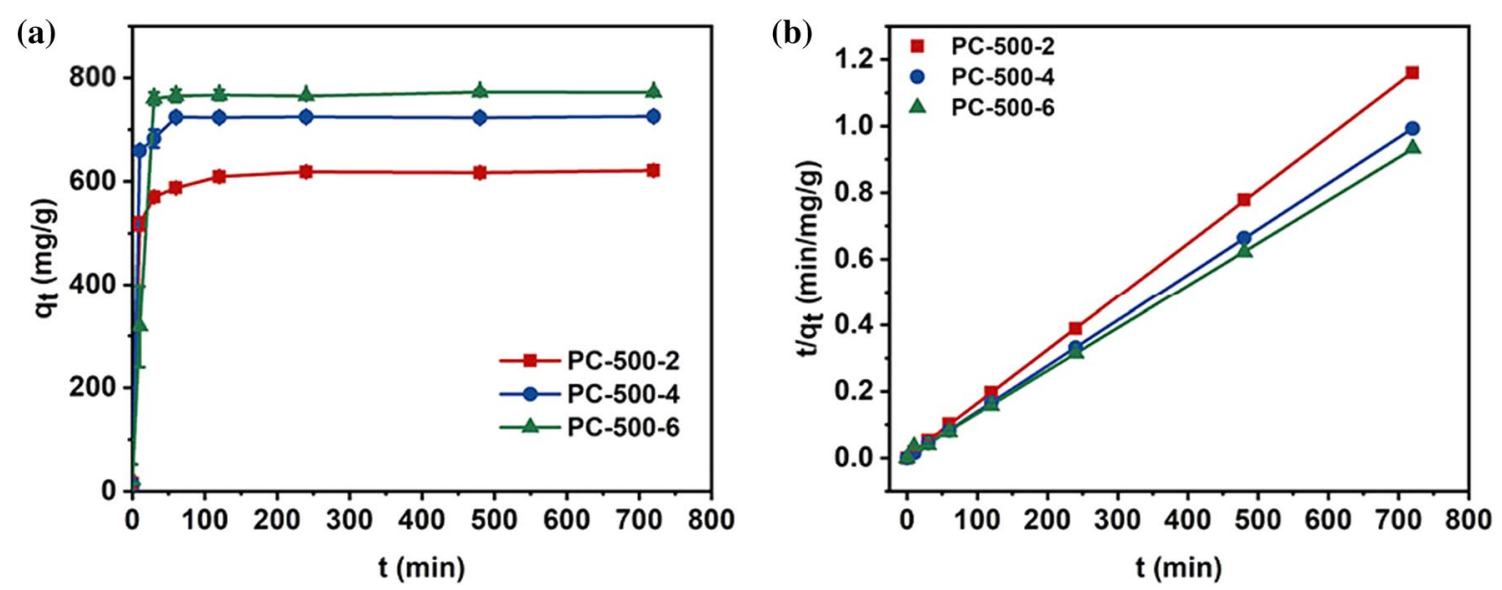

Fig. 5 Kinetic curves of a the pseudo-second-order kinetic model, $\mathbf{b}$ PC-500-Y for the adsorption of MB. (Experimental conditions: MB concentration was $250 \mathrm{mg} / \mathrm{L}$ for PC-500-2, $300 \mathrm{mg} / \mathrm{L}$ for PC-500-4 and PC-500-6 and adsorbent concentration was $20 \mathrm{mg} / \mathrm{L}$.)

Table 3 Kinetic parameters of the pseudo-second-order kinetic model for MB on PC-500-Y

\begin{tabular}{|c|c|c|c|c|c|c|c|}
\hline Absorbent & Slope & Intercept & $C_{0}(\mathrm{mg} / \mathrm{l})$ & $q_{e^{\prime}} \exp (\mathrm{mg} / \mathrm{g})$ & $q_{e}, c a l(\mathrm{mg} / \mathrm{g})$ & $k_{2}(\mathrm{~g} / \mathrm{mg} / \mathrm{min})$ & $R^{2}$ \\
\hline PC-500-2 & 0.0016 & 0.0034 & 250 & 616.27 & 621.12 & $7.60^{*} 10^{-4}$ & 0.9997 \\
\hline$P C-500-4$ & 0.0014 & 0.0010 & 300 & 724.09 & 724.647 & $2.07^{*-3}$ & 0.9999 \\
\hline PC-500-6 & 0.0013 & 0.0055 & 300 & 768.79 & 781.25 & $2.96^{*-4}$ & 0.9994 \\
\hline
\end{tabular}

Table 4 Thermodynamic parameters for the adsorption of MB on PC-500-6

\begin{tabular}{lllll}
\hline Absorbent & $\boldsymbol{t}\left({ }^{\circ} \mathrm{C}\right)$ & $\boldsymbol{\Delta} \boldsymbol{G}(\mathbf{k J} / \mathbf{m o l})$ & $\boldsymbol{\Delta} \boldsymbol{H}(\mathbf{k J} / \mathbf{m o l})$ & $\boldsymbol{\Delta S}(\mathrm{J} / \mathbf{m o l ~ K})$ \\
\hline PC-500-6 & 20 & $-1.07^{*} 10^{4}$ & -0.91 & -2.56 \\
& 30 & $-9.45^{*} 10^{3}$ & & \\
& 40 & $-7.17^{*} 10^{3}$ & & \\
\hline
\end{tabular}

$$
\begin{aligned}
& \ln \left(\frac{\mathrm{q}_{\mathrm{e}}}{\mathrm{C}_{\mathrm{e}}}\right)=\frac{-\Delta \mathrm{H}}{\mathrm{RT}}+\frac{\Delta \mathrm{S}}{\mathrm{R}}, \\
& \Delta G=\Delta H-T \Delta S,
\end{aligned}
$$

where $q_{e}(\mathrm{mg} / \mathrm{g})$ is the adsorption capacity, $C_{e}(\mathrm{mg} / \mathrm{L})$ is the MB concentrations at equilibrium, $\Delta G(\mathrm{~kJ} / \mathrm{mol})$ is the standard Gibbs free energy change, $\Delta H(\mathrm{~kJ} / \mathrm{mol})$ is the standard enthalpy change, $\Delta S(\mathrm{~J} / \mathrm{mol} \mathrm{K})$ is the standard entropy change, $\mathrm{R}(8.314 \mathrm{~J} / \mathrm{mol} / \mathrm{K})$ is the gas constant, and $\mathrm{T}(\mathrm{K})$ is the absolute temperature.

The values of $\Delta G, \Delta H$ and $\Delta S$ were calculated and shown in Table 4 . The negative enthalpy change $(\Delta H$ $=-0.91 \mathrm{~kJ} / \mathrm{mol}$ ) indicates that the adsorption reaction is an exothermal reaction, which is supported by the decreased adsorption capability with increasing of the temperature. The negative value of $\Delta G$ reveals that adsorption of $\mathrm{MB}$ onto membrane is a spontaneous and feasible process. The negative entropy change $(\Delta S=-2.56 \mathrm{~kJ} / \mathrm{mol})$ indicates that the adsorption decreases randomly at the solid-solute interface during the adsorption. The thermodynamic calculations indicated that methylene blue adsorption was spontaneous and exothermic in nature.

Figure $6 \mathrm{a}$ shows clearly the linear relationship between $q_{m}$ and specific surface area $\left(S_{B E T}\right)$. It can be observed that the adsorption of MB has a strong correlation with SSA, indicating that SSA has a great impact on adsorption ability. For example, among all AC samples, PC-500-6 has the highest adsorption value of $917.43 \mathrm{mg} / \mathrm{g}\left(q_{m}\right)$ due to the highest SSA of $3203 \mathrm{~m}^{2} / \mathrm{g}$. Moreover, the pore volume and pore size distribution also have some influence on the adsorption capacity. In Table 1, AC samples with higher value of $V_{(0.8-3.0}$ $\mathrm{nm}) / V_{\text {total }}$ have higher adsorption capacity. For example, PC-500-2, PC-500-4 and PC-500-6 show high adsorption values $(751.88,884.96$ and $917.43 \mathrm{mg} / \mathrm{g}$ ) as well as high values of $V_{(0.8-3.0 \mathrm{~nm})} / V_{\text {total }}(53.2 \%, 88.1 \%$ and $86.9 \%)$. To understand the underlying mechanism more deeply, the molecular size of $\mathrm{MB}$ and pore size of $\mathrm{AC}$ are compared. As shown in Fig. 6c, the size of MB is 

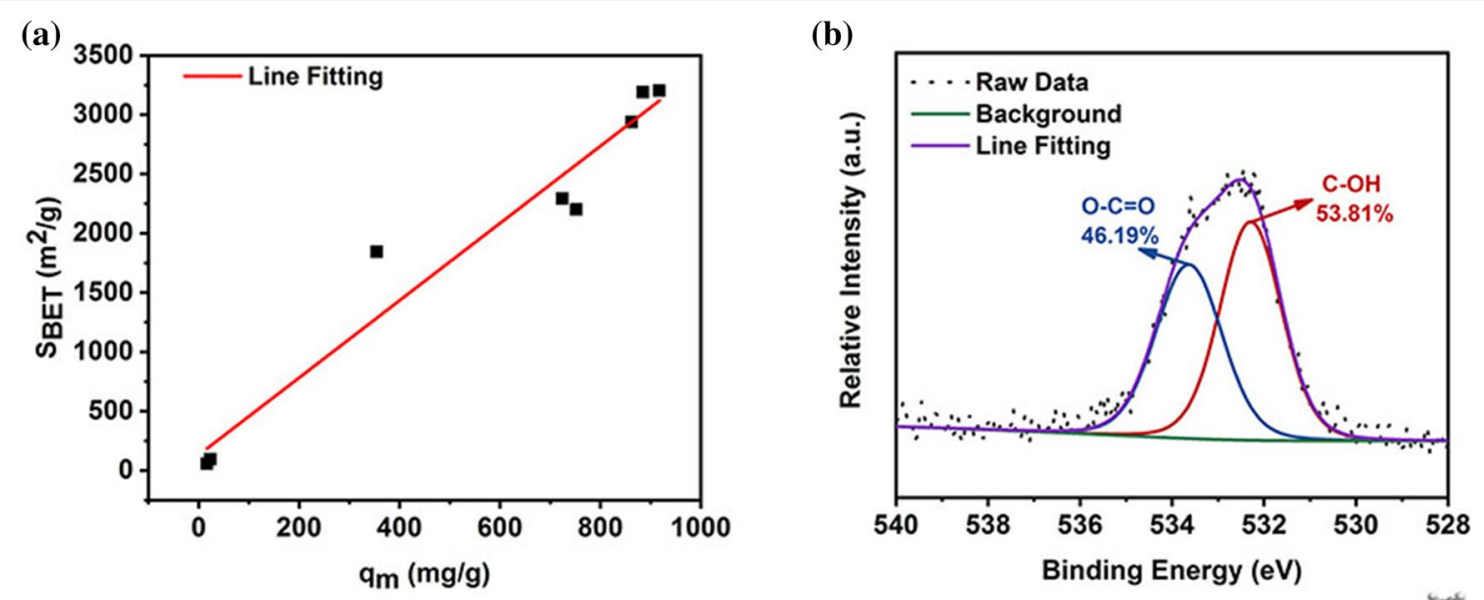

(c)

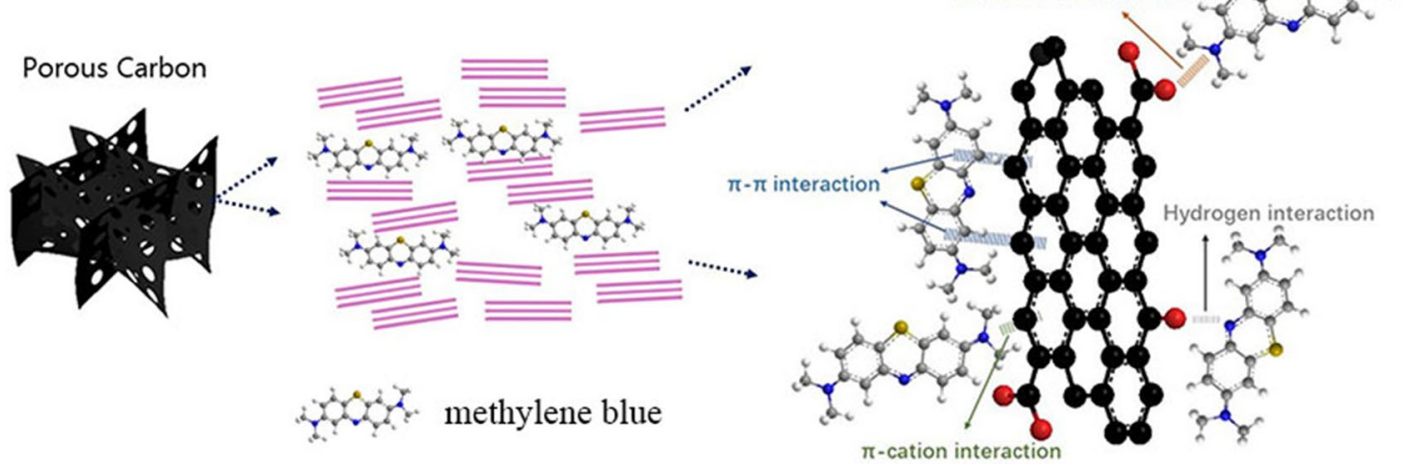

Fig. 6 a Correlations between the $q_{m}$ and $S_{B E T}\left(R^{2}=0.95022\right)$; b high-resolution C 1s XPS spectra of PC-500-6; $\mathbf{c}$ a scheme for MB adsorption in the $3 \mathrm{D}$ porous carbon

about $0.7 \mathrm{~nm} \times 1.6 \mathrm{~nm}$, which can easily get into the pores with a diameter in the range of $0.8 \mathrm{~nm}$ to $3.0 \mathrm{~nm}$. The dye adsorption capacity is also related to the pore volume of AC samples. As depicted in Table 1, the adsorption capacity increases as the pore volume was enhanced, such as the values of $V_{\text {total }}$ for PC-500-2, PC-500-4 and PC-500-6 being 1.0, 1.7 and $2.1 \mathrm{~cm}^{3} / \mathrm{g}$, and the corresponding adsorption values are 751.88 , 884.96 and $917.43 \mathrm{mg} / \mathrm{g}$, respectively. Based on above analyses, the adsorption capacity of AC is determined by three parameters: SSA, pore volume, and pore size distribution. The larger SSA provides more sites for the adsorption of $\mathrm{MB}$ molecules, and the suitable pore size distribution and large pore volume can also increase the adsorption capacity as well. Moreover, according to the high-resolution O 1s XPS spectra of PC-500-6, there were small quantities of oxygen-containing group on the surface of porous carbon. The presence of carboxylic and hydroxyl groups is considered to be good adsorption sites for cationic dyes driven by electrostatic interaction.
The adsorption of MB dyes over the PC-500-6 adsorbent are collectively driven by the $\pi-\pi$ interaction between the graphitic domains of carbon skeleton and aromatic rings of $\mathrm{MB}$ dye molecules, hydrogen linkages between the oxygen functionalities of PC-500-6 and nitrogen/ oxygen centers in the dye molecules (Fig. 6c).

\section{Conclusions}

In summary, a 3D porous carbon was prepared from jujube at optimized carbonization temperatures and activation agent addition. The resulting $3 \mathrm{D}$ porous carbon shows a specific surface area $\left(3203 \mathrm{~m}^{2} / \mathrm{g}\right)$ and suitable pore size distribution, leading to an excellent adsorption performance on both cationic dye and anionic dye from an aqueous solution, such as methylene blue (MB) and methylene (MO). PC-500-6 displays the high performance in adsorption $\mathrm{MB}$ and $\mathrm{MO}$ as high as $917.43 \mathrm{mg} / \mathrm{g}$ and $1281.39 \mathrm{mg} / \mathrm{g}$, respectively. The present method paves a way to prepare biomass-derived $\mathrm{AC}$ for the removal of organic dyes from polluted water. 


\begin{abstract}
Abbreviations
MB: Methylene blue; MO: Methylene orange; SSA: Specific surface area; $S_{\text {BET }}$ : Specific surface area was calculated from BET method; $V_{\text {total }}$ Total pore volume; $V_{(0.8-3.0 \mathrm{~nm})}$ : The pore volume when the pore size in the range of 0.8 to $3.0 \mathrm{~nm} ; q_{e}$ : Amount of MB adsorption at equilibrium; $c_{0}$ and $c_{e}(\mathrm{mg} / \mathrm{l})$ : The liquid-phase concentration of MB before adsorption and at equilibrium; $V:$ The volume of the aqueous solution; $W$ : The mass of the adsorbent; $I_{D} l_{G}$ : Ratio of the $\mathrm{D}$ band to $\mathrm{G}$ band; $K_{L}$ : The Langmuir adsorption constant; $a_{m}$ : Langmuir monolayer adsorbate capacity; $K_{f}$ and $n:$ The Freundlich constants; $K$ : Absolute temperature; $R$ : The universal gas constant $(8.314 \mathrm{~J} / \mathrm{mol} / \mathrm{K}) ; K_{T}$ : The equilibrium binding constant; $B_{T}$ : Related to the heat of adsorption and constant value of Temkin isotherm; $k_{1}$ : The rate constant of the pseudo-first-order kinetic model for the adsorption; $k_{2}$ : The rate constant of the pseudo-second-order kinetic model for adsorption; $h$ : Initial adsorption rate.
\end{abstract}

\section{Supplementary Information}

The online version contains supplementary material available at https://doi. org/10.1186/s12302-021-00527-6.

Additional File 1: Figure S1. (a) SEM and (b-d) corresponding EDS Mapping images of $\mathrm{PC}-500-6$ indicating the existence of $C$ and $O$ element. Figure S2. Photo of the (a) MB and (b) MO solutions before and after adsorption on the PC-500-6. Figure S3. Effect of (a) initial concentration $\left(20^{\circ} \mathrm{C}\right.$, $12 \mathrm{~h}, \mathrm{pH}: 6) ;(\mathbf{b}) \mathrm{pH}\left(\mathrm{C}_{0}: 350 \mathrm{mg} / \mathrm{L}, 20^{\circ} \mathrm{C}, 12 \mathrm{~h}\right) ;(\mathbf{c})$ adsorption temperature $\left(C_{0}: 350 \mathrm{mg} / \mathrm{L}, 12 \mathrm{~h}, \mathrm{pH}: 6\right)$; (d) adsorption time $\left(C_{0}: 350 \mathrm{mg} / \mathrm{L}, 20^{\circ} \mathrm{C}, \mathrm{pH}: 6\right)$; (e) ion strengthen $\left(C_{0}: 350 \mathrm{mg} \mathrm{mg} / \mathrm{L}, 20^{\circ} \mathrm{C}, 12 \mathrm{~h}, \mathrm{pH}: 6\right)$ and (f) the reusability $\left(\mathrm{C}_{0}: 350 \mathrm{mg} / \mathrm{L}, 20^{\circ} \mathrm{C}, 12 \mathrm{~h}, \mathrm{pH}: 6\right)$ for MB adsorption on PC-500-6. Figure S4. The point of zero charge of $P C-500-6$. Figure S5. Equilibrium adsorption isotherms of (a) C-800 (b) PC-800-2 (c) PC-800-4 and PC-800-6; and (d) Langmuir, (e) Freundlich and (f) Temkin isotherms of MB on C-800 and PC-800-Y. (20 mg of C-800, PC-800-2 or PC-800-4/6 added to a $50 \mathrm{~mL}$ MB solution (10-80 mg/L, $100-500 \mathrm{mg} / \mathrm{L}$ or $150-550 \mathrm{mg} / \mathrm{L}$ ) at a designated concentration after stirring for 12 h.) Figure S6. The pseudo first-order kinetic model of PC-500-Y for the adsorption of MB. (Experimental conditions: $M B$ concentration $=250 \mathrm{mg} / \mathrm{L}$ for PC-500-2, $300 \mathrm{mg} / \mathrm{L}$ for PC-500-4 and PC-500-6 and adsorbent concentration $=20 \mathrm{mg} / \mathrm{L})$. Figure S7. (a) Kinetic curves; (b) pseudo first-order kinetic model and (c) the pseudo second-order kinetic model (b) of PC-800-Y for the adsorption of MB. (Experimental conditions: MB concentration was 250 mg/L for PC-800-2, $300 \mathrm{mg} / \mathrm{L}$ for PC-800-4 and PC-800-6 and adsorbent concentration was 20 mg/L). Figure S8. (a) Equilibrium adsorption isotherms; (b) Langmuir, (c) Freundlich and (d) Temkin isotherms of MO on PC-500-6. (20 mg of PC-500-6 added to a $50 \mathrm{~mL} \mathrm{MO}$ solution (100-600 mg/L) at a designated concentration after stirring for $12 \mathrm{~h}$.) Table S1. Langmuir, Freundlich and Temkin isotherm parameters of C-800 and PC-800-Y for MB. Table S2. Comparison table of adsorption capacities of $\mathrm{MB}$ on different adsorbents. Table S3. Kinetic parameters of the pseudo first-order kinetic model for MB on the PC-500-Y. Table S4. Kinetic parameters of the pseudo second-order kinetic model for MB on the PC-800-Y. Table S5. Langmuir, Freundlich and Temkin isotherm parameters of PC-500-6 for MO.

\section{Acknowledgements}

Not applicable

\section{Authors' contributions}

$J L$ conceived the idea, prepared, tested and wrote the manuscript. $R H, S L$ and TT reviewed and corrected the manuscript. SM contributed with the surface chemistry analysis. SW and XC conceived the project and contributed to the writing of the manuscript. All authors reviewed the manuscript. All authors read and approved the final manuscript.

\section{Funding}

The authors acknowledge financial support from National Science Centre, Poland, within OPUS UMO-2017/25/B/ST8/02702 and the General Project Fund of Liaoning Education Department (No. LJGD2019014).

Availability of data and materials Not applicable.

\section{Declarations}

Ethics approval and consent to participate

Not applicable.

\section{Consent for publication}

Not applicable.

\section{Competing interests}

The authors declare that they have no competing interest.

\section{Author details}

${ }^{1}$ Faculty of Chemical Technology and Engineering, West Pomeranian University of Technology, Piastów Ave. 42, 71-065 Szczecin, Poland. ${ }^{2}$ Institut Für Chemie, Chemnitz University of Technology, AG Elektrochemie, 09107 Chemnitz, Germany. ${ }^{3}$ Institute of Chemistry, Saint Petersburg State University, St. Petersburg 199034, Russia. ${ }^{4}$ State Key Laboratory of Materials-Oriented Chemical Engineering, School of Energy Science and Engineering, Nanjing Tech University, Nanjing 211816, Jiangsu, China. ${ }^{5}$ School of Environment and Chemical Engineering, Shenyang University of Technology, Shenyang 110870, China. ${ }^{6}$ Changchun Institute of Applied Chemistry, Chinese Academy of Sciences, Changchun 130022, China.

Received: 19 April 2021 Accepted: 7 July 2021

Published online: 21 August 2021

\section{References}

1. Tavangar T, Karimi M, Rezakazemi M, Reddy KR, Aminabhavi TM (2020) Textile waste, dyes/inorganic salts separation of cerium oxide-loaded loose nanofiltration polyethersulfone membranes. Chem Eng J 385:14

2. Basheer AA (2018) Chemical chiral pollution: Impact on the society and science and need of the regulations in the 21 (st) century. Chirality 30:402-406

3. Basheer AA (2018) New generation nano-adsorbents for the removal of emerging contaminants in water. J Mol Liq 261:583-593

4. Zhang L, Sellaoui L, Franco D, Dotto GL, Bajahzar A, Belmabrouk H, Bonilla-Petriciolet A, Oliveira MLS, Li ZC (2020) Adsorption of dyes brilliant blue, sunset yellow and tartrazine from aqueous solution on chitosan: Analytical interpretation via multilayer statistical physics model. Chem Eng J 382:7

5. Ali I, Alharbi OML, ZA A L, Alwarthan A, Al-Mohaimeed A M, (2019) Preparation of a carboxymethylcellulose-iron composite for uptake of atorvastatin in water. Int J Biol Macromol 132:244-253

6. Katheresan V, Kansedo J, Lau SY (2018) Efficiency of various recent wastewater dye removal methods: a review. J Environ Chem Eng 6:4676-4697

7. Xiong S-W, Yu Y, Wang P, Liu M, Chen S-h, Yin X-z, Wang L-X, Wang H (2020) Growth of $\mathrm{AgBr} / \mathrm{Ag}_{3} \mathrm{PO}_{4}$ heterojunction on chitosan fibers for degrading organic pollutants. Adv Fiber Mater 2:246-255

8. Sun Y, Mwandeje JB, Wangatia LM, Zabihi F, Nedeljković J, Yang S (2020) Enhanced photocatalytic performance of surface-modified $\mathrm{TiO}_{2}$ nanofibers with rhodizonic acid. Adv Fiber Mater 2:118-122

9. Ali I, Alharbi OML, Alothman ZA, Badjah AY (2018) Kinetics, thermodynamics, and modeling of amido black dye photodegradation in water using $\mathrm{Co} / \mathrm{TiO}_{2}$ nanoparticles. Photochem Photobiol 94:935-941

10. Li Q, Li YH, Ma XM, Du QJ, Sui KY, Wang DC, Wang CP, Li HL, Xia YZ (2017) Filtration and adsorption properties of porous calcium alginate membrane for methylene blue removal from water. Chem Eng J 316:623-630

11. Youssef AM, Ahmed Al, El-Bana UA (2012) Adsorption of cationic dye (MB) and anionic dye (AG 25) by physically and chemically activated carbons developed from rice husk. Carbon Lett 13:61-72

12. Yagub MT, Sen TK, Afroze S, Ang HM (2014) Dye and its removal from aqueous solution by adsorption: A review. Adv Colloid Interface Sci 209:172-184

13. Rafatullah M, Sulaiman O, Hashim R, Ahmad A (2010) Adsorption of methylene blue on low-cost adsorbents: a review. J Hazard Mater 177:70-80

14. Gong J, Liu J, Chen X, Jiang Z, Wen X, Mijowska E, Tang T (2015) Converting real-world mixed waste plastics into porous carbon nanosheets 
with excellent performance in the adsorption of an organic dye from wastewater. J Mater Chem A 3:341-351

15. Liu L, Gao ZY, Su XP, Chen X, Jiang L, Yao JM (2015) Adsorption removal of dyes from single and binary solutions using a cellulose-based bioadsorbent. Acs Sustain Chem Eng 3:432-442

16. Zhang WL, Li HH, Tang JM, Lu HJ, Liu YQ (2019) Ginger straw wastederived porous carbons as effective adsorbents toward methylene blue. Molecules 24:8

17. Szczesniak B, Phuriragpitikhon J, Choma J, Jaroniec M (2020) Recent advances in the development and applications of biomass-derived carbons with uniform porosity. J Mater Chem A 8:18464-18491

18. Santoso E, Ediati R, Kusumawati Y, Bahruji H, Sulistiono DO, Prasetyoko D (2020) Review on recent advances of carbon based adsorbent for methylene blue removal from waste water. Mater Today Chem 16:21

19. Ukanwa KS, Patchigolla K, Sakrabani R, Anthony E, Mandavgane S (2019) A review of chemicals to produce activated carbon from agricultural waste biomass. Sustainability 11:35

20. Cazetta AL, Pezoti O, Bedin KC, Silva TL, Paesano Junior A, Asefa T, Almeida VC (2016) Magnetic activated carbon derived from biomass waste by concurrent synthesis: efficient adsorbent for toxic dyes. Acs Sustain Chem Eng 4:1058-1068

21. Islam MA, Tan IAW, Benhouria A, Asif M, Hameed BH (2015) Mesoporous and adsorptive properties of palm date seed activated carbon prepared via sequential hydrothermal carbonization and sodium hydroxide activation. Chem Eng J 270:187-195

22. Islam MT, Hyder A, Saenz-Arana R, Hernandez C, Guinto T, Ahsan MA, Alvarado-Tenorio B, Noveron JC (2019) Removal of methylene blue and tetracycline from water using peanut shell derived adsorbent prepared by sulfuric acid reflux. J Environ Chem Eng 7:12

23. Gupta K, Gupta D, Khatri OP (2019) Graphene-like porous carbon nanostructure from Bengal gram bean husk and its application for fast and efficient adsorption of organic dyes. Appl Surf Sci 476:647-657

24. Nasrullah A, Saad B, Bhat AH, Khan AS, Danish M, Isa MH, Naeem A (2019) Mangosteen peel waste as a sustainable precursor for high surface area mesoporous activated carbon: characterization and application for methylene blue removal. J Clean Prod 211:1190-1200

25. Wen X, Liu HS, Zhang L, Zhang J, Fu C, Shi XZ, Chen XC, Mijowska E, Chen MJ, Wang DY (2019) Large-scale converting waste coffee grounds into functional carbon materials as high-efficient adsorbent for organic dyes. Bioresource Technol 272:92-98

26. Wan H, Hu X (2020) Sulfur-doped honeycomb-like carbon with outstanding electrochemical performance as an anode material for lithium and sodium ion batteries. J Colloid Interface Sci 558:242-250

27. Zhou C, Wang D, Li A, Pan E, Liu H, Chen X, Jia M, Song H (2020) Threedimensional porous carbon doped with $\mathrm{N}, \mathrm{O}$ and $\mathrm{P}$ heteroatoms as high-performance anode materials for sodium ion batteries. Chem Eng J 380:77

28. Chen B, Yang Z, Ma G, Kong D, Xiong W, Wang J, Zhu Y, Xia Y (2018) Heteroatom-doped porous carbons with enhanced carbon dioxide uptake and excellent methylene blue adsorption capacities. Micropor Mesopor Mat 257:1-8

29. Ma C, Min J, Gong J, Liu X, Mu X, Chen X, Tang T (2020) Transforming polystyrene waste into 3D hierarchically porous carbon for high-performance supercapacitors. Chemosphere 253:126755

30. Shi X, Zhang S, Chen X, Tang T, Mijowska E (2020) Three dimensional graphene/carbonized metal-organic frameworks based high-performance supercapacitor. Carbon 157:55-63

31. Burakova EA, Dyachkova TP, Rukhov AV, Tugolukov EN, Galunin EV, Tkachev AG, Basheer AA, Ali I (2018) Novel and economic method of carbon nanotubes synthesis on a nickel magnesium oxide catalyst using microwave radiation. J Mol Liq 253:340-346

32. Liu X, Ma C, Wen Y, Chen X, Zhao X, Tang T, Holze R, Mijowska E (2021) Highly efficient conversion of waste plastic into thin carbon nanosheets for superior capacitive energy storage. Carbon 171:819-828
33. Liu X, Wen Y, Chen X, Tang T, Mijowska E (2020) Co-etching effect to convert waste polyethylene terephthalate into hierarchical porous carbon toward excellent capacitive energy storage. Sci Total Environ 723:138055

34. Li JX, Michalkiewicz B, Min JK, Ma CD, Chen XC, Gong J, Mijowska E, Tang $T$ (2019) Selective preparation of biomass-derived porous carbon with controllable pore sizes toward highly efficient $\mathrm{CO}_{2}$ capture. Chem Eng J 360:250-259

35. Qiu Z, Wang Y, Bi X, Zhou T, Zhou J, Zhao J, Miao Z, Yi W, Fu P, Zhuo S (2018) Biochar-based carbons with hierarchical micro-meso-macro porosity for high rate and long cycle life supercapacitors. J Power Sources 376:82-90

36. Wei H, Chen H, Fu N, Chen J, Lan G, Qian W, Liu Y, Lin H, Han S (2017) Excellent electrochemical properties and large $\mathrm{CO}_{2}$ capture of nitrogendoped activated porous carbon synthesised from waste longan shells. Electrochim Acta 231:403-411

37. Ma C, Liu X, Min J, Li J, Gong J, Wen X, Chen X, Tang T, Mijowska E (2020) Sustainable recycling of waste polystyrene into hierarchical porous carbon nanosheets with potential applications in supercapacitors. Nanotechnology 31:35402

38. Ali I, Burakov AE, Melezhik AV, Babkin AV, Burakova IV, Neskomornaya MEA, Galunin EV, Tkachev AG, Kuznetsov DV (2019) Removal of Copper(II) and Zinc(II) ions in water on a newly synthesized polyhydroquinone/ graphene nanocomposite material: kinetics, thermodynamics and mechanism. ChemistrySelect 4:12708-12718

39. Chen L, Li Y, Du Q, Wang Z, Xia Y, Yedinak E, Lou J, Ci L (2017) High performance agar/graphene oxide composite aerogel for methylene blue removal. Carbohydr Polym 155:345-353

40. Ali I, Alharbi OML, ZA A L, Al-Mohaimeed A M, Alwarthan A, (2019) Modeling of fenuron pesticide adsorption on CNTs for mechanistic insight and removal in water. Environ Res 170:389-397

41. Islam MA, Ahmed MJ, Khanday WA, Asif M, Hameed BH (2017) Mesoporous activated carbon prepared from $\mathrm{NaOH}$ activation of rattan (Lacosperma secundiflorum) hydrochar for methylene blue removal. Ecotoxicol Environ Saf 138:279-285

42. Gong J, Liu J, Jiang Z, Wen X, Mijowska E, Tang T, Chen X (2015) A facile approach to prepare porous cup-stacked carbon nanotube with high performance in adsorption of methylene blue. J Colloid Interface Sci 445:195-204

43. Yang J, Qiu K (2010) Preparation of activated carbons from walnut shells via vacuum chemical activation and their application for methylene blue removal. Chem Eng J 165:209-217

44. Wan X, Zhan Y, Long Z, Zeng G, He Y (2017) Core@double-shell structured magnetic halloysite nanotube nano-hybrid as efficient recyclable adsorbent for methylene blue removal. Chem Eng J 330:491-504

45. Somsesta N, Sricharoenchaikul V, Aht-Ong D (2020) Adsorption removal of methylene blue onto activated carbon/cellulose biocomposite films: Equilibrium and kinetic studies. Mater Chem Phys 240:122221

46. Ali I, Alharbi OML, Alothman ZA, Alwarthan A (2018) Facile and ecofriendly synthesis of functionalized iron nanoparticles for cyanazine removal in water. Colloids Surf B Biointerfaces 171:606-613

\section{Publisher's Note}

Springer Nature remains neutral with regard to jurisdictional claims in published maps and institutional affiliations. 